\title{
Contribution of vitamin D status as a determinant of cardiometabolic risk factors: a structural equation model, National Food and Nutrition Surveillance
}

Bahareh Nikooyeh and Tirang R. Neyestani ${ }^{*}$ (1)

\begin{abstract}
Background: Structural equation modeling (SEM) is a method used to evaluate linear causal relationships among variables. This study aimed to investigate the direct and indirect effects of serum $25(\mathrm{OH}) \mathrm{D}$ on certain cardiovascular risk factors using SEM.

Methods: An analytical cross-sectional study was conducted in six provinces of Iran. Subjects $(n=922)$, aged 19-65 years, were selected from National Food and Nutrition Surveillance. The assessments were sun-exposure behavior, anthropometric and biochemical measurements. A series of SEM models were tested and the model with the best fit indices was considered for use in the structural part of the model. Based on the literature review of previous theoretical models and supporting bivariate analyses, an overall SEM examined direct or indirect associations among observed and latent variables. We put the demographic, duration of sun exposure, anthropometric and metabolic variables in our model.

Results: The paths between serum $25(\mathrm{OH}) \mathrm{D}$ and $\mathrm{BMl}$ were inverse and statistically significant, whereas age showed a positive association with $\mathrm{BMI}(B=0.06, p<0.001)$, both direct (st. effect $=0.11, p=0.01)$ and indirect via vitamin $D$ (st. effect $=-0.02, p=0.01$ ). The results confirmed that serum $25(\mathrm{OH}) \mathrm{D}$ concentration is a predictor for latent variable of lipid profile $(\mathrm{B}=-0.13, p=0.01)$ both through direct $(p=0.02)$ and indirect effects via $\mathrm{BMI}(p=$ 0.01).
\end{abstract}

Conclusion: Serum $25(\mathrm{OH})$ D concentration is a predictor of BMI and also a latent variable of lipid profile via direct and indirect effects. It can also attenuate the harmful effect of age on BMI and lipid profile particularly in women.

Keywords: Vitamin D, Structural equation modeling, Cardiometabolic risk factors, Blood lipid profile, BMI, Surveillance

\footnotetext{
* Correspondence: neytr@yahoo.com; tneyestani@nnftri.ac.ir

National Nutrition and Food Technology Research Institute and Faculty of Nutrition Science and Food Technology, Shahid Beheshti University of Medical Sciences, Tehran 1981619573, Iran
}

(c) The Author(s). 2021 Open Access This article is licensed under a Creative Commons Attribution 4.0 International License, which permits use, sharing, adaptation, distribution and reproduction in any medium or format, as long as you give appropriate credit to the original author(s) and the source, provide a link to the Creative Commons licence, and indicate if changes were made. The images or other third party material in this article are included in the article's Creative Commons licence, unless indicated otherwise in a credit line to the material. If material is not included in the article's Creative Commons licence and your intended use is not permitted by statutory regulation or exceeds the permitted use, you will need to obtain permission directly from the copyright holder. To view a copy of this licence, visit http://creativecommons.org/licenses/by/4.0/ The Creative Commons Public Domain Dedication waiver (http://creativecommons.org/publicdomain/zero/1.0/) applies to the data made available in this article, unless otherwise stated in a credit line to the data. 


\section{Background}

Vitamin D is a steroid hormone and also an essential nutrient. Mother Nature has equipped human body with a machinery to build vitamin $\mathrm{D}$ upon skin exposure to direct sunlight. However, urbanization has broken up this natural relation between man and sun. Consequently, humans are prone to vitamin D deficiency (VDD) unless they receive sufficient amounts of the vitamin through dietary sources and supplements [1]. Among the earliest recognized functions of vitamin $D$, its effect on calcium homeostasis and musculoskeletal system has been well appreciated especially with the remarkable increasing rate of VDD-related osteoporosis [2, 3]. However, unlike its calcemic functions, vitamin $\mathrm{D}$ non-calcemic actions have been controversial [4], among which the effect on blood lipids and related cardiovascular risk has been a big argument [5-11]. Several observational studies have reported cardioprotective effects of vitamin D notably through its optimizing action on blood lipid components [12]. However, evidence for causality of this association is limited [13]. A meta-analysis reported the decreased mortality risk in those supplemented with vitamin $\mathrm{D}$ as compared to the controls (Relative risk $=0.93$ ) [14]. It seems that the rise in mortality in people with low serum 25(OH) D concentrations may be particularly linked to CVD [15, 16] and its risk factors including increased blood pressure [17], blood glucose [18] and body mass index (BMI) [19]. However, reports on the relationship between circulating $25(\mathrm{OH}) \mathrm{D}$ and serum lipids as the major risk factor for CVD have been inconsistent $[7,8,20,21]$.

Considering high prevalence of suboptimal vitamin D status around the world, vitamin D supplementation as a cost-effective intervention may be a straightforwardly correctable risk factor for CVD prevention [8]. The important concern is whether vitamin D has a beneficial effect on serum lipids and cardiovascular morbidity.

The structural equation modeling (SEM) is a method used to evaluate linear causal relationships among variables and a powerful statistical tool taking into account the modeling of independent and correlated errors for examining complex research questions and analyzing the relationships among multiple variables [22]. Literally, SEM is an extension of the general linear model that enables measurement of both direct and indirect effects of variables and incorporate models with multiple dependent variables by using several regression equations simultaneously [23, 24]. This study was undertaken to investigate the direct and indirect effects of serum $25(\mathrm{OH}) \mathrm{D}$ on body mass index (BMI) and lipid profile among adult subjects using SEM approach.

\section{Methods}

\section{Ethical statement}

The study was conducted according to the Declaration of Helsinki. Written informed consent was obtained from all subjects prior to data collection. The protocols of National Food and Nutrition Surveillance (NFNS) were approved by the Ethics Committee of National Nutrition and Food Technology Research Institute (NNFTRI).

\section{Design and participants}

Subjects $(n=922), 426$ men and 496 women aged 1965 years, were selected randomly from registered households of NFNS, a national health and nutrition program that has been implemented in Iran since 2013 by NNFT RI in collaboration with Nutrition Office of the Deputy of Health of the Ministry of Health and United Nations Children's Fund (UNICEF). More details can be found elsewhere [25]. Briefly, participants who met the inclusion criteria (generally healthy, not using dietary supplements containing vitamin D) were randomly selected from the registered households from six provinces of Iran with different latitudes including West Azarbaijan (latitude $37.5^{\circ} \mathrm{N}, 45.0^{\circ} \mathrm{E}$ ), Semnan (latitude $35.5^{\circ} \mathrm{N}$, $53.3^{\circ} \mathrm{E}$ ), Lorestan (latitude $33.4^{\circ} \mathrm{N}, 48.3^{\circ} \mathrm{E}$ ), South Khorasan (latitude $32.8^{\circ} \mathrm{N}, 59.2^{\circ} \mathrm{E}$ ), Khoozestan (latitude $31.3^{\circ} \mathrm{N}, 48.6^{\circ} \mathrm{E}$ ) and Fars (latitude $29.6^{\circ} \mathrm{N}, 52.5^{\circ}$ E) using multistage cluster random sampling method. Data were collected in mid-winter (20 January to 20Febraury).

\section{Assessments}

The protocols of all measurements were prepared and standardized by scientific committee of NFNS. Research teams were trained in workshop sessions held centrally to further make sure that data collection was harmonized across all regions.

\section{Sun exposure behavior}

The questionnaire for evaluation of sun exposure behavior comprised three questions on daily sun exposure during the last 14 days including (i) whether the subject had a direct sun exposure (answers: no exposure, 10-60 min, 60$120 \mathrm{~min}$, more than $120 \mathrm{~min}$ ), (ii) if yes, at what time of day (answers: 7-10, 10-15, 15-17), and (iii) sunscreen use habits (answers: never, sometimes, often, always).

\section{Anthropometric measurements}

Standing height was measured without shoes to the nearest of $0.1 \mathrm{~cm}$. Weight was measured to the nearest of $0.1 \mathrm{~kg}$ and body mass index was calculated as weight $(\mathrm{kg}) /$ height $^{2}(\mathrm{~m})$. 


\section{Biochemical analyses}

A venous blood sample was collected from each participant after an overnight fast. Separated serum samples were aliquoted and stored at $-80{ }^{\circ} \mathrm{C}$ until analysis day. Serum $25(\mathrm{OH})$ D concentrations were measured by enzyme immunoassay (EIA) method (Diasource, OttigniesLouvain-la-Neuve, Belgium) with the aid a plate reader (Stat Fax 3200, Awareness, Palm City, FL, USA).

Total cholesterol (TC), high-density lipoprotein-cholesterol (HDL-C), triglycerides (TG) and low-density lipoproteincholesterol (LDL-C) were measured using enzymatic methods (Pars-Azmoon, Tehran, Iran) and an auto-analyzer (Selecta E; Vitalab, Holliston, Netherlands).

\section{Data analyses}

Descriptive statistics was employed for population characteristics. Participants' characteristics were summarized as mean \pm standard deviation (SD) for continuous variables and as percentages (\%) for categorical variables. Independent sample $t$ test and chi-square test were used to compare variables between men and women.

\section{Model structure}

The theoretical models that "vitamin D status influences cardio-metabolic risk factors including BMI and lipid profile" and that "sun exposure behavior and latitude of living place associate with vitamin D status" were tested using a structural equation modeling (SEM). First, we used measurement models to determine which of the serum lipid components and sun exposure questions could define the latent constructs of lipid profile and sun exposure behavior. Then, a series of SEM models were tested with direct and indirect pathways of associations between variables. The model with the best fit according to the values of several fit indices was considered for use in the structural part of the model. Gender was considered as a mediator variable. Bootstrap approaches were used to the significance of the total, direct and indirect effect among variables. The model's goodness of fit was examined using three fit indices including relative chi-square $\left(\mathrm{x}^{2} / \mathrm{df}\right)$, range 2 to 5 , the comparative fit index $(\mathrm{CFI})>0.90$, and the root mean square error of approximation (RMSEA) $<0.06$ [26]. Twelve subjects $(1.3 \%)$ were excluded from the analysis by reason of missing data on demographics and other outcome variables. The significant differences were not detected among the selected variables (age, gender, BMI and serum $25(\mathrm{OH}) \mathrm{D})$ between the included $(n=910)$ and excluded $(n=12)$ cases. Analyses were conducted using statistical program IBM SPSS 21.0 and IBM SPSS AMOS

Table 1 The characteristics of participants based on gender

\begin{tabular}{|c|c|c|c|}
\hline Variables & Men $(n=424)$ & Women $(n=486)$ & $p$ value $^{*}$ \\
\hline Age, (years) & $39.3 \pm 7.9$ & $38.6 \pm 8.3$ & 0.220 \\
\hline Body mass index, $\left(\mathrm{kg} / \mathrm{m}^{2}\right)$ & $26.7 \pm 4.1$ & $27.8 \pm 4.8$ & $<0.001$ \\
\hline \multicolumn{4}{|l|}{ Sun exposure duration, n (\%) } \\
\hline No exposure & 45 (10.6) & $115(23.7)$ & \multirow[t]{4}{*}{$<0.001$} \\
\hline 10-60 min & $164(38.7)$ & $279(57.4)$ & \\
\hline $60-120 \mathrm{~min}$ & $71(16.7)$ & $60(12.3)$ & \\
\hline More than $120 \mathrm{~min}$ & $144(34.0)$ & $32(6.6)$ & \\
\hline \multicolumn{4}{|l|}{ Time of day (\%) } \\
\hline $7-10$ & $62(14.6)$ & $123(25.3)$ & \multirow[t]{3}{*}{$<0.001$} \\
\hline $10-15$ & $306(72.2)$ & $304(62.6)$ & \\
\hline $15-17$ & $56(13.2)$ & $59(12.1)$ & \\
\hline \multicolumn{4}{|l|}{ Sunscreen use (\%) } \\
\hline Never & $383(90.3)$ & $199(40.9)$ & \multirow[t]{4}{*}{$<0.001$} \\
\hline Sometimes & $25(5.9)$ & $120(24.7)$ & \\
\hline Often & $4(0.9)$ & $55(11.3)$ & \\
\hline Always & $12(2.8)$ & $112(23.0)$ & \\
\hline 25-hydroxy vitamin D (nmol/L) & $27.3 \pm 15.2$ & $25.9 \pm 17.5$ & 0.206 \\
\hline Triglyceride (mg/dL) & $148.9 \pm 83.6$ & $114.8 \pm 61.2$ & $<0.001$ \\
\hline Total cholesterol (mg/dL) & $169.3 \pm 35.0$ & $167.7 \pm 33.1$ & 0.485 \\
\hline LDL (mg/dL) & $97.9 \pm 28.5$ & $95.3 \pm 27.8$ & 0.158 \\
\hline $\mathrm{HDL}(\mathrm{mg} / \mathrm{dL})$ & $41.7 \pm 12.3$ & $49.5 \pm 11.6$ & $<0.001$ \\
\hline
\end{tabular}

Values are mean \pm SD or number (\%), $p$-values for between-group differences were assessed using t.test or chi-square test, as appropriate 
20.0 (Armonk, NY). $P$ value $<0.05$ was considered significant for all analyses.

\section{Results}

\section{Descriptive statistics}

The descriptive statistics of the characteristics of the participants by gender are demonstrated in Table 1. Women had a higher BMI and serum HDL, as compared with men $(p<0.001)$. However, women exposed themselves to sun less and used sunscreen more frequently than men $(p<$ $0.001)$. There was no significant difference in serum $25(\mathrm{OH}) \mathrm{D}$ concentrations between two genders $(p=0.22)$.

\section{Structural equation modeling}

The variables associated with the latent variable of sun exposure behavior were, in order of strength of association, duration of sun exposure, time of day and sunscreen use and latent variable of lipid profile was defined by four variables of serum TC, LDL-C, TG and HDL-C, in order of strength of association.

Based on the literature review of previous theoretical models and supporting bivariate analyses, an overall SEM examined direct or indirect associations among observed and latent variables. We put the demographic, duration of sun exposure, anthropometric and metabolic variables in our SEM (Fig. 1). The model demonstrated a good fit to the data $\left(\mathrm{x}^{2} / \mathrm{df}=2.50 ; \mathrm{CFI}=0.98 ; \mathrm{TLI}=0.97\right.$; RMSEA $=0.03$ ).
The paths between serum 25(OH) D and age (st. effect $=0.08, \mathrm{~B}=0.15, p=0.03$ ) and sun exposure behavior (st. effect $=0.23, \mathrm{~B}=9.73, p<0.001$ ) were statistically significant. Thus, these variables had a direct effect on vitamin D status. However, the latitude of living place did not show a significant direct effect on circulating $25(\mathrm{OH}) \mathrm{D}$ and sun exposure behavior mediated the effect of latitude on vitamin D status (st. effect $=0.03, p=$ 0.04). Moreover, $25(\mathrm{OH}) \mathrm{D}$ concentration was inversely associated with BMI, whereas age showed a positive association with BMI $(\mathrm{B}=0.06, p<0.001)$. The effect of age on BMI was both direct (st. effect $=0.11, p=0.009$ ) and indirect via vitamin $\mathrm{D}$ (st. effect $=-0.02, p=0.006$ ).

The results confirmed the hypothesis that serum $25(\mathrm{OH}) \mathrm{D}$ concentration is a predictor for latent variable of lipid profile $(\mathrm{B}=-0.13, \mathrm{p}=0.006)$ both through direct $(p=0.02)$ and indirect effects $(p=0.01)$. The indirect effect of serum $25(\mathrm{OH}) \mathrm{D}$ on lipid profile was via BMI (Table 2).

\section{Multi-group analysis}

Execution of the multi-group analysis in the model demonstrated that some paths were statistically different between men and women. Analysis revealed significant differences $(p=0.03)$ of path coefficients of serum $25(\mathrm{OH}) \mathrm{D}$ and sun exposure behaviors between men $(\mathrm{B}=0.36, p=0.01)$ and women $(\mathrm{B}=0.18, p=0.049)$. In addition, these analyses showed that age was significant

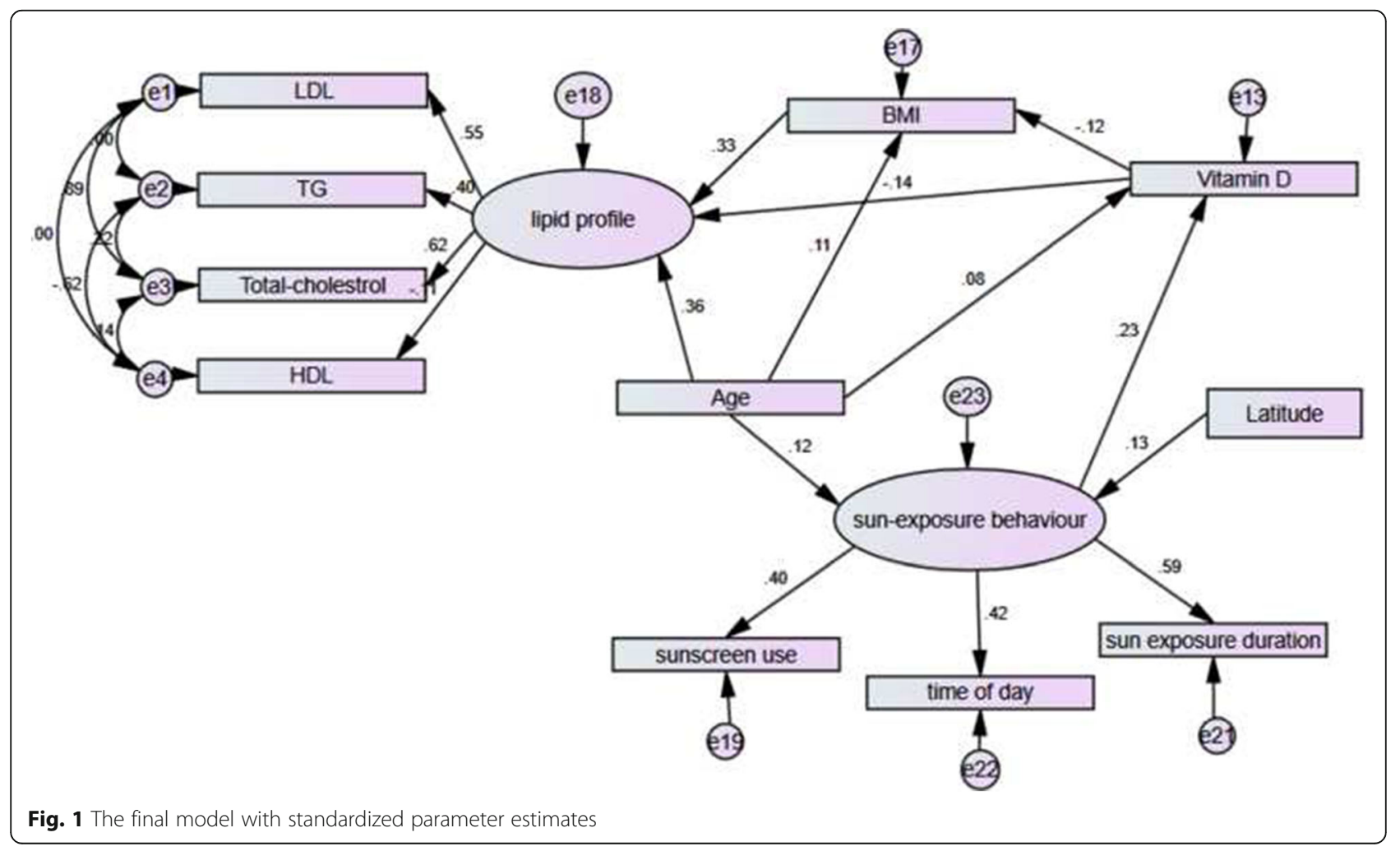


Table 2 The coefficients and the corresponding $P$ values of the standardized total, direct and indirect effects between variables in model

\begin{tabular}{|c|c|c|c|c|c|c|}
\hline & St. total effect & $p$-value & St. direct effect & $p$-value & St. indirect effect & $p$ value \\
\hline Age $\rightarrow$ Vit D & 0.103 & 0.008 & 0.075 & 0.006 & 0.028 & 0.006 \\
\hline Age $\rightarrow \mathrm{BMl}$ & 0.099 & 0.012 & 0.111 & 0.012 & -0.012 & 0.005 \\
\hline Age $\Rightarrow$ lipid profile & 0.377 & 0.006 & 0.358 & 0.009 & 0.019 & 0.251 \\
\hline Sun-exposure $\boldsymbol{\rightarrow}$ vit D & 0.230 & 0.012 & 0.230 & 0.012 & - & - \\
\hline Sun-exposure $\boldsymbol{\Rightarrow}$ BMI & -0.027 & 0.021 & - & - & -0.027 & 0.021 \\
\hline Sun-exposure $\boldsymbol{\rightarrow}$ lipid profile & -0.04 & 0.005 & - & - & -0.04 & 0.005 \\
\hline Vit $\mathrm{D} \rightarrow \mathrm{BMI}$ & -0.117 & 0.013 & -0.117 & 0.013 & - & - \\
\hline Vit $D \Rightarrow$ lipid profile & -0.175 & 0.011 & -0.136 & 0.023 & -0.039 & 0.012 \\
\hline BMI $\Rightarrow$ lipid profile & 0.331 & 0.014 & 0.331 & 0.014 & - & - \\
\hline
\end{tabular}

predictor of $\mathrm{BMI}$ in women $(\mathrm{B}=0.11, p<0.001)$ but not in men $(\mathrm{B}=0.01, p=0.68)$ and path coefficients were different between two genders $(p=0.007)$. There was a significant direct effect of age on lipid profile in both men $(\mathrm{B}=0.94, p<0.001)$ and women $(\mathrm{B}=0.26, p=0.02)$, this effect was also significantly different between two genders $(p<0.001)$. However, multi-group analysis revealed no significant differences between men and women in path coefficients of vitamin D and BMI $(p=0.84)$, vitamin D and lipid profile $(p=0.660)$, or BMI and lipid profile $(p=0.79)$.

\section{Discussion}

To our knowledge, this is the first study to provide evidence of the relationships among sun exposure behavior, serum $25(\mathrm{OH}) \mathrm{D}, \mathrm{BMI}$ and lipid profile among adult population using SEM method. The major advantage of SEM method is its ability to examine the complex relationships among variables using a systematic approach with a simultaneous management of measurement errors [22].

\section{Vitamin D, sun exposure and latitude}

In continuation of previous works on determinants of vitamin D status [27], we found that sun exposure behavior, independent of the latitude of living place, was an important determinant of serum $25(\mathrm{OH})$ D concentration. In addition, populations in lower latitudes tend to have lower sun exposure behavior score which may diminish their dermal vitamin D synthesis. However, multi-group analysis with the aim to compare path coefficients between men and women showed that sun exposure behavior was a stronger predictor of circulating $25(\mathrm{OH}) \mathrm{D}$ in men than in women. One unit increment in sun exposure behavior score was associated with increase in serum $25(\mathrm{OH}) \mathrm{D}$ by $45 \mathrm{nmol} / \mathrm{L}$ in men but only $8 \mathrm{nmol} / \mathrm{L}$ in women.

The effect of latitude on vitamin D status has already been reported $[28,29]$. In winter, vitamin $\mathrm{D}$ synthesis may be insufficient and even negligible in the latitudes higher than 35 degree due to lower intensity of sunlight. Notwithstanding, a study in Korean people showed that 20-30 min of sun exposure per day during summer and fall was not adequate in achieving sufficient circulating 25(OH) D concentrations [30]. Along the same line, a study showed that sun exposure during summer when limited just to face and hands (the usual exposure sites in Iran due to cultural reasons) may not suffice to protect against vitamin D deficiency [31, 32].

\section{Efficiency of dermal synthesis of vitamin D according to sex}

The model proposed by the current study suggests that individuals living in higher latitudes would synthesize more vitamin D in winter if they had sufficient sun exposure, as compared with the individuals who live in lower latitudes but have "sun getaway" behavior. However, circulating $25(\mathrm{OH}) \mathrm{D}$ concentrations in only a minority of the studied population reached the proposed optimal level of $50 \mathrm{nmol} / \mathrm{L}$. In addition, our results indicate that a latent variable comprised of duration of sun exposure, time of day and sunscreen use, may adequately represent the construct of sun behavior that showed a significant association with 25(OH)D.

\section{Vitamin D and BMI}

We found an inverse association between BMI and $25(\mathrm{OH}) \mathrm{D}$ which is in accord with some other reports [33, 34]. Previous investigations demonstrated that age, in both sexes, is an important predictor of BMI in all BMI ranges [35, 36]. However, we found that circulating $25(\mathrm{OH}) \mathrm{D}$ concentration influences the relationship between age and BMI. Along the same line, BMI has been recently proposed as an age-independent predictor of vitamin D status in women [37]. This provides an indirect linking path, in addition to the direct association.

Altogether, this observation proposes that with increasing $25(\mathrm{OH}) \mathrm{D}$ levels, the age-dependent increment in BMI may be attenuated (increasing of $10 \mathrm{nmol} / \mathrm{L}$ in 
serum 25(OH) D is associated with reduction of BMI by $\left.0.3 \mathrm{~kg} / \mathrm{m}^{2}\right)$.

\section{Vitamin D and lipid profile}

The direct and indirect effects of vitamin D on latent variable of lipid profile are noteworthy. The model showed that increasing serum $25(\mathrm{OH}) \mathrm{D}$ concentration was linked to decreased chance of lipid profile derangements. In other words, vitamin D was able to lessen the adverse effects of BMI and age on lipid profile.

Comparing our results with the existing data is not easy as most investigations have focused on association between lipid profile components and circulating $25(\mathrm{OH}) \mathrm{D}$ concentrations. The beneficial effect of vitamin D on components of blood lipid profile, CVD and myocardial infarction risk has been observed in several randomized controlled trials [38-41]. On the contrary, some studies did not report any significant effect [4244]. As a result, the effect of vitamin D status on lipid profile has been controversial [45]. Our findings provide, for the first time through SEM approach, more convincing evidence for beneficial effects of vitamin $\mathrm{D}$ on blood lipids. One of the advantages of using structural equation models is the focus on latent constructs rather than on variables used to measure these constructs. Unlike previous studies, we considered the modulating effect of vitamin D on lipid profile as a latent construct rather than its components as single variables.

\section{Conclusion}

Altogether, these observations propose that serum $25(\mathrm{OH}) \mathrm{D}$ concentration is a predictor of latent variable of lipid profile and BMI via direct and indirect effects. Also, with increasing serum $25(\mathrm{OH}) \mathrm{D}$ concentrations, the age-dependent increment in BMI and dyslipidemia may be attenuated. In addition, vitamin $\mathrm{D}$ may be able to lessen the adverse effects of BMI and age on lipid profile. Nevertheless, the cross-sectional nature of this study hinders a conclusive evaluation of causal associations. Though SEM is applied to evaluate linear causal relationships among variables [22], precise evaluation of causality still warrants further clinical trial studies.

\section{Acknowledgements \\ The National Food and Nutrition Surveillance (NFNS) is financially supported by United Nations International Children's Emergency Fund (UNICEF) in Iran, Community Nutrition Office of the Iran Ministry of Health, and NNFTRI in order of their financial contributions. All laboratory bench works were performed at the Laboratory of Nutrition Research, NNFTRI. We wish to thank all participants for taking part in this project. We also appreciate our provincial contributors, their teams and the provincial deputies of health for their assistance, especially Somayeh Asghari, Fariba Babai, Fariboz Bojdi, Mostafa Hosseini, Razieh Shenavar, Mahnoosh Sahebdel, Ma'asoomeh Moradi, Sakineh Noori.}

\section{Authors' contributions}

TRN and BN are the main executing researchers of FNS in Iran, a program supported by NNFTRI, the Community Nutrition Office of IrMOH and UNICEF.
The study was designed by TRN and BN. All statistical analyses were done by $\mathrm{BN}$. The preliminary draft of this paper was written by $\mathrm{BN}$, which was then edited and finalized by TN.

\section{Funding}

NFNS was funded by UNICEF, Community Nutrition Office of the Iran Ministry of Health and the National Nutrition and Food Technology Research Institute (NNFTRI). However, this piece of work received no specific fund. Designing, collection, analyses and interpretation of data as well as writing the manuscript were done solely by the authors.

Availability of data and materials

The datasets used and/or analyzed during the current study are available from the corresponding author on reasonable request.

\section{Declarations}

Ethics approval and consent to participate

The study was conducted according to the Declaration of Helsinki. Written informed consent was obtained from all subjects prior to data collection. The protocols of National Food and Nutrition Surveillance were approved by the Ethics Committee of National Nutrition and Food Technology Research Institute (reference: ir.sbmu.nnftri.rec.1396.170).

\section{Consent for publication}

Not applicable for the current analysis.

\section{Competing interests}

The authors declare they have no competing interest.

Received: 27 September 2020 Accepted: 22 September 2021 Published online: 09 October 2021

\section{References}

1. Kimball SM, Holick MF. Official recommendations for vitamin D through the life stages in developed countries. Eur J Clin Nutr. 2020;74(11):1514-8.

2. Bell, T.D., M.B. Demay, and S.A.M. Burnett-Bowie, The biology and pathology of vitamin D control in bone. J Cell Biochem, 2010. 111(1): p. 7-13, 1, DOl: https://doi.org/10.1002/jcb.22661.

3. Ballane G, Cauley JA, Luckey MM, el-Hajj Fuleihan G. Worldwide prevalence and incidence of osteoporotic vertebral fractures. Osteoporos Int. 2017;28(5): 1531-42. https://doi.org/10.1007/s00198-017-3909-3.

4. Pludowski, P., et al., Editorial: Classic and Pleiotropic Actions of Vitamin D. CLASSIC AND PLEIOTROPIC ACTIONS OF VITAMIN D, 2007: p. 4.

5. Gao H, Li Y, Yan W, Gao F. The Effect of Vitamin D Supplementation on Blood Lipids in Patients with Polycystic Ovary Syndrome: A Meta-Analysis of Randomized Controlled Trials. Int J Endocrinol. 2021;2021.

6. Liss Y, Frishman WH. Vitamin D: a cardioprotective agent? Cardiol Rev. 2012; 20(1):038-44. https://doi.org/10.1097/CRD.0b013e31822c5380.

7. Barbarawi M, Kheiri B, Zayed Y, Barbarawi O, Dhillon H, Swaid B, et al. Vitamin D supplementation and cardiovascular disease risks in more than 83000 individuals in 21 randomized clinical trials: a meta-analysis. JAMA Cardiol. 2019;4(8):765-76. https://doi.org/10.1001/jamacardio.2019.1870.

8. Lee K, Kim J. Serum vitamin D status and metabolic syndrome: a systematic review and dose-response meta-analysis. Nutr Res Pract. 2021;15(3):329-45. https://doi.org/10.4162/nrp.2021.15.3.329.

9. Preiss D, Sattar N. Research digest: vitamin D supplementation. Lancet Diabetes Endocrinol. 2019;7(2):91. https://doi.org/10.1016/S2213-8587(19)3 0007-5.

10. Izzo M, Carrizzo A, Izzo C, Cappello E, Cecere D, Ciccarelli M, et al. Vitamin D: Not Just Bone Metabolism but a Key Player in Cardiovascular Diseases. Life (Basel). 2021;11(5). https://doi.org/10.3390/life11050452.

11. Zittermann, A., et al., Vitamin D and Cardiovascular Disease: An Updated Narrative Review. Int J Mol Sci, 2021. 22(6), Vitamin D and Cardiovascular Disease: An Updated Narrative Review, 22, 6, DOI: https://doi.org/10.3390/ ijms22062896.

12. Wang Y, Si S, Liu J, Wang Z, Jia H, Feng K, et al. The associations of serum lipids with vitamin D status. PLoS One. 2016;11(10):e0165157. https://doi. org/10.1371/journal.pone.0165157.

13. Jorde, R. and G. Grimnes, Vitamin D and lipids: do we really need more studies? 2012, Am Heart Assoc 
14. Autier P, Gandini S. Vitamin D supplementation and total mortality: a metaanalysis of randomized controlled trials. Arch Intern Med. 2007;167(16): 1730-7. https://doi.org/10.1001/archinte.167.16.1730.

15. Pilz S, Dobnig H, Nijpels G, Heine RJ, Stehouwer CDA, Snijder MB, et al. Vitamin D and mortality in older men and women. Clin Endocrinol (Oxf). 2009;71(5):666-72. https://doi.org/10.1111/j.1365-2265.2009.03548.x.

16. Al-khalidi B, et al. Metabolically healthy obesity, vitamin D, and all-cause and cardiometabolic mortality risk in NHANES III. Clin Nutr. 2019;38(2):820-8. https://doi.org/10.1016/j.clnu.2018.02.025.

17. Beveridge LA, Struthers AD, Khan F, Jorde R, Scragg R, Macdonald HM, et al. Effect of vitamin $D$ supplementation on blood pressure: a systematic review and meta-analysis incorporating individual patient data. JAMA Intern Med. 2015;175(5):745-54. https://doi.org/10.1001/jamainternmed.2015.0237.

18. Need AG, O'Loughlin PD, Horowitz M, Nordin BEC. Relationship between fasting serum glucose, age, body mass index and serum 25 hydroxyvitamin D in postmenopausal women. Clin Endocrinol (Oxf). 2005;62(6):738-41. https://doi.org/10.1111/j.1365-2265.2005.02288.x

19. Cheng S, Massaro JM, Fox CS, Larson MG, Keyes MJ, McCabe EL, et al. Adiposity, cardiometabolic risk, and vitamin D status: the Framingham heart study. Diabetes. 2010;59(1):242-8. https://doi.org/10.2337/db09-1011.

20. Moy F-M, Bulgiba A. High prevalence of vitamin D insufficiency and its association with obesity and metabolic syndrome among Malay adults in Kuala Lumpur, Malaysia. BMC Public Health. 2011;11(1):735. https://doi.org/1 0.1186/1471-2458-11-735.

21. Fernández-Arroyo S, Hernández-Aguilera A, de Vries MA, Burggraaf B, van der Zwan E, Pouw N, et al. Effect of Vitamin D3 on the postprandial lipid profile in obese patients: a non-targeted Lipidomics study. Nutrients. 2019; 11(5):1194. https://doi.org/10.3390/nu11051194.

22. Beran TN, Violato C. Structural equation modeling in medical research: a primer. BMC Res Notes. 2010;3(1):267. https:/doi.org/10.1186/1756-0500-3-267.

23. Kline RB. Principles and practice of structural equation modeling. 4th ed New York: Guilford Press; 2016.

24. Hartwell ML, Khojasteh J, Wetherill MS, Croff JM, Wheeler D. Using Structural Equation Modeling to Examine the Influence of Social, Behavioral, and Nutritional Variables on Health Outcomes Based on NHANES Data: Addressing Complex Design, Nonnormally Distributed Variables, and Missing Information. Curr Dev Nutrition. 2019;3(5). https://doi.org/10.1093/ $\mathrm{cdn} / \mathrm{nzz010}$

25. Nikooyeh B, Abdollahi Z, Hajifaraji M, Alavi-majd H, Salehi F, Yarparvar AH, et al. Vitamin D status and cardiometabolic risk factors across latitudinal gradient in Iranian adults: National food and nutrition surveillance. Nutr Health. 2017:23(2):87-94. https://doi.org/10.1177/0260106017702918.

26. Hu LT, Bentler PM. Cutoff criteria for fit indexes in covariance structure analysis: conventional criteria versus new alternatives. Struct Equ Model Multidiscip J. 1999:6(1):1-55. https://doi.org/10.1080/10705519909540118.

27. Tønnesen R, Hovind PH, Jensen LT, Schwarz P. Determinants of vitamin D status in young adults: influence of lifestyle, sociodemographic and anthropometric factors. BMC Public Health. 2016;16(1):385. https://doi.org/1 0.1186/s12889-016-3042-9.

28. Leary PF, Zamfirova I, Au J, McCracken W. Effect of latitude on vitamin D levels. J Am Osteopath Assoc. 2017;117(7):433-9. https://doi.org/10.7556/ja oa.2017.089

29. Jelinek GA, Marck CH, Weiland TJ, Pereira N, van der Meer DM, Hadgkiss EJ. Latitude, sun exposure and vitamin D supplementation: associations with quality of life and disease outcomes in a large international cohort of people with multiple sclerosis. BMC Neurol. 2015;15(1):132. https://doi.org/1 0.1186/s12883-015-0394-1.

30. Joh H-K, Hwang SS, Cho BL, Lim CS, Jung SE. Effect of sun exposure versus oral vitamin D supplementation on serum 25-hydroxyvitamin D concentrations in young adults: a randomized clinical trial. Clin Nutr. 2019; 39(3):727-36. https://doi.org/10.1016/j.clnu.2019.03.021

31. Webb A, Kazantzidis A, Kift R, Farrar M, Wilkinson J, Rhodes L. Meeting vitamin $D$ requirements in white Caucasians at UK latitudes: providing a choice. Nutrients. 2018;10(4):497. https://doi.org/10.3390/nu10040497.

32. Webb A, Kazantzidis A, Kift R, Farrar M, Wilkinson J, Rhodes L. Colour counts: sunlight and skin type as drivers of vitamin D deficiency at UK latitudes. Nutrients. 2018;10(4):457. https://doi.org/10.3390/nu10040457.

33. Lemacks JL, Ilich JZ, Liu PY, Shin H, Ralston PA, Cui M, et al. Dietary influence on calcitropic hormones and adiposity in Caucasian and African American postmenopausal women assessed by structural equation modeling (SEM). J Nutr Health Aging. 2016;20(6):602-10. https://doi.org/10.1 007/s12603-015-0637-2.

34. Martins D, Wolf M, Pan D, Zadshir A, Tareen N, Thadhani R, et al. Prevalence of cardiovascular risk factors and the serum levels of 25 -hydroxyvitamin $D$ in the United States: data from the third National Health and nutrition examination survey. Arch Intern Med. 2007;167(11):1159-65. https://doi. org/10.1001/archinte.167.11.1159.

35. Moon K, Krems C, Heuer T, Roth A, Hoffmann I. Predictors of BMI vary along the BMI range of German adults-results of the German National Nutrition Survey II. Obes Facts. 2017;10(1):38-49. https://doi.org/10.1159/000456665.

36. Arabshahi S, Lahmann PH, Williams GM, van der Pols JC. Predictors of change in weight and waist circumference: 15-year longitudinal study in Australian adults. Eur J Clin Nutr. 2014;68(3):309-15. https://doi.org/10.1038/ ejcn.2013.260

37. Delle Monache S, di Fulvio P, lannetti E, Valerii L, Capone L, Nespoli MG, et al. Body mass index represents a good predictor of vitamin D status in women independently from age. Clin Nutr. 2019;38(2):829-34. https://doi. org/10.1016/j.clnu.2018.02.024.

38. Shab-Bidar S, Neyestani TR, Djazayery A, Eshraghian MR, Houshiarrad A, Gharavi A', et al. Regular consumption of vitamin D-fortified yogurt drink (Doogh) improved endothelial biomarkers in subjects with type 2 diabetes: a randomized double-blind clinical trial. BMC Med. 2011:9(1):125. https://doi. org/10.1186/1741-7015-9-125

39. Barzegari M, Sarbakhsh P, Mobasseri M, Noshad H, Esfandiari A, Khodadadi $B$, et al. The effects of vitamin D supplementation on lipid profiles and oxidative indices among diabetic nephropathy patients with marginal vitamin D status. Diab Metab Syndr. 2019;13(1):542-7. https://doi.org/10.101 6/j.dsx.2018.11.008.

40. Nikooyeh B, Neyestani TR, Farvid M, Alavi-Majd H, Houshiarrad A, Kalayi A, et al. Daily consumption of vitamin D- or vitamin D + calcium-fortified yogurt drink improved glycemic control in patients with type 2 diabetes: a randomized clinical trial. Am J Clin Nutr. 2011;93(4):764-71. https://doi.org/1 0.3945/ajcn.110.007336.

41. Acharya P, et al. The Effects of Vitamin D Supplementation and 25Hydroxyvitamin D Levels on the Risk of Myocardial Infarction and Mortality. J Endocr Soc. 2021;5(10):bvab124.

42. Yiu Y-F, Yiu KH, Siu CW, Chan YH, Li SW, Wong LY, et al. Randomized controlled trial of vitamin $D$ supplement on endothelial function in patients with type 2 diabetes. Atherosclerosis. 2013;227(1):140-6. https://doi.org/10.1 016/j.atherosclerosis.2012.12.013.

43. Patel P, Poretsky L, Liao E. Lack of effect of subtherapeutic vitamin D treatment on glycemic and lipid parameters in type 2 diabetes: a pilot prospective randomized trial. J Diabetes. 2010;2(1):36-40. https://doi.org/1 0.1111/j.1753-0407.2009.00057.x.

44. Heravifard S, Neyestani TR, Nikooyeh B, Alavi-Majd H, Houshiarrad A, Kalayi A, et al. Regular consumption of both vitamin D- and calcium- and vitamin D-fortified yogurt drink is equally accompanied by lowered blood lipoprotein (a) and elevated apoprotein A1 in subjects with type 2 diabetes: a randomized clinical trial. J Am Coll Nutr. 2013;32(1):26-30. https://doi. org/10.1080/07315724.2013.767659.

45. Challoumas D. Vitamin D supplementation and lipid profile: what does the best available evidence show? Atherosclerosis. 2014;235(1):130-9. https:// doi.org/10.1016/j.atherosclerosis.2014.04.024.

\section{Publisher's Note}

Springer Nature remains neutral with regard to jurisdictional claims in published maps and institutional affiliations.

Ready to submit your research? Choose BMC and benefit from:

- fast, convenient online submission

- thorough peer review by experienced researchers in your field

- rapid publication on acceptance

- support for research data, including large and complex data types

- gold Open Access which fosters wider collaboration and increased citations

- maximum visibility for your research: over $100 \mathrm{M}$ website views per year

At $\mathrm{BMC}$, research is always in progress.

Learn more biomedcentral.com/submissions 